\title{
Arduino Based Automated Braking Control System to Enhance the Safety at Low Light and Long Stressed Drive Conditions
}

\author{
Bhaskara. P, Eriki Ananda. K*, Venkataramana. V \\ Department of Mechanical Engineering, VEMU Institute of Technology, Kothakota-517112, AP, India. \\ *Corresponding Author: Eriki Ananda. K, Department of Mechanical Engineering, VEMU Institute of \\ Technology, Kothakota-517112, AP, India.
}

\begin{abstract}
Assurance of the tribological conduct of brake effects under low light and long stressed drive is vital and basic errands which can significantly help the driver of the 4-wheel. Most examinations or measure the variations by circuitous techniques and acknowledge them as evident outcomes. The new Arduino board controlled, intuitive brake effects grating analyzer exhibited in this examination was created for this reason. The significant parts of the machine, which are worked at the same time, include: a relative weight controlled air power control pack, a mechanical transmission framework with object grasp sensor, and a brake and mechanization control with Arduino board investigation interface. In this study the Arduino board performance was carried to evaluate the distance at which the vehicle comes to rest position. The validity of the setup is checked in order to assist the drivers during over stress conditions like long drives and long duty hours.
\end{abstract}

Keywords: Arduino board, Safety with low light, long stressed drive and braking system,

\section{INTRODUCTION}

Countless mishaps today can be faulted for issues identified with the slowing mechanisms of the vehicles. Once the vehicle is begun, it must be ceased some place. Brakes are connected on the wheels to stop the vehicle. Before applying the brakes, speeding up is discharged to stop the fuel supply framework in this manner the motor builds up no more energy to run the vehicle, and after that Clutch is additionally withdrawn which associates the motor from transmission framework [1]. In this manner, when the vehicle is standing, the motor is as yet running at lingering. Make enough deceleration to stop the vehicle as fast as the driver wishes, without surpassing the drivers comfort level as to pedal exertion or pedal travel. The stopping mechanism coverts the dynamic vitality into warm Brakes are the most vital segments of a vehicle as they are the essential source to convey the vehicle to an end [2]. Inability to brake can bring about a catastrophe and makers are progressively attempting to make breaking on their vehicles productive for better traveler wellbeing. Diverse vehicles utilize distinctive sorts of brakes; while some utilize drum brake, some utilize a circle brake and after that obviously there are included innovations, for example, ABS and ESP which additionally help better braking. The brakes are connected which quit moving of the wheels out and about and consequently the vehicle is halted [3].The current arrangement of mishap avoidance utilizes liquor finder, neck and head development, casualty investigation; these advances have their impediments which should be destroyed. Driver exhaustion is one such issue because of which mischance happen [4].

Ultrasonic going and identifying gadgets influence utilization of high-recurrence to sound waves to recognize the nearness of a question and its range. These frameworks either measure the resound impression of the sound waves from objects or distinguish the interference of the sound shaft as the items go between the transmitter and collector. A ultrasonic sensor regularly uses a transducer that creates an electrical yield beat because of the got ultrasonic vitality. In such case, the even opening edge must be no less than 8 degrees for a between vehicle separation of 75 meter. The vertical opening is settled to be 1 degree and is situated in such an approach to maintain a strategic distance from blame perusing because of the street conditions. The thought is to keep the mischance by computing the separation. There have been numerous innovations to maintain a strategic distance from the mischance however none of it utilized ultrasonic and corridor sensors. The constraints of 
different innovations have been decreased to extraordinary degree. A strategy for keeping a mishap utilizing an innovation is called ultrasonic $[8,11]$.

This venture concentrates on building an easy to understand gadget that spends significant time in distinguishing interruptions other than doing short proximity hindrance discovery [5]. Vehicle wellbeing can be enhanced by reckoning a crash before it happens and in this way giving extra time to convey security advances. Notices can resemble ringer if the driver is moving toward a pothole or any hindrance, driver might be cautioned in cutting edge with respect to what the street involves [6]. The undertaking's definitive point in this manner concluded as, one to construct a general, simple to-utilize and adaptable framework that can counteract lethal mishaps. As found in the previously mentioned issue with the convectional brakes the issue is emerges because of the erosion between at least two rubbing parts [7].

Thus pneumatic brakes can be utilized as a substitution which is absolutely frictionless. What's more, because of which there is no doubt of wear and tear of parts and superfluous temperature issues as there is no rubbing in this stopping mechanism this outcomes in stable productivity of the slowing mechanism for a more drawn out administration traverse. Furthermore, it brings about longer life expectancy of the stopping mechanism with no wear and tear [9]. This likewise gives the response for the substitution of cooling framework. In this manner, the pneumatic brakes give the responses for the inquiries that emerge in the convectional slowing mechanisms. Properties of the material utilized for brake cushions and linings, and the brakes turn out to be less proficient [10].

\section{Objectives:}

The primary objective of this case study is:

a. To check the utility of Arduino board to activate the pneumatic brake system.

b. To find the halt distance at various vehicle speeds as well as minimum distance before collision.

c. Determine the effective speed range of operations of the selected board.

d. To validate the utility of the system when the driver is inattentive due to long drive or long duty hours.

\section{Methodology}

This proposed framework can be effectively actualized close extraordinary populated territories. The energy of the proposed framework lies in its adaptability and capacity of advancement with little equipment changes, for example, changing as far as possible and speed control strategies utilizing the product of the base station in immaterial measure of time. The proposed framework depends on Arduino innovation for gathering information identified with speed and transmitting the signals to operate the pneumatic brake to decelerate the vehicle at appropriate distance. An attempt to make progressive development in the field of brakes is been carried out in the present study.

\subsection{Experimental Setup}

The entire setup is laid on an iron frame structure, where air cylinder with a control valve is located at one end and wheel on the other end. The wheel is placed on an axle with bearings and is driven by a motor with the help of belt drive; the pulleys are in the velocity ratio of 1:7. A pneumatic brake is connected to the air cylinder through a slave cylinder, a solenoid valve is placed in between pneumatic and brake cylinder which is operated by Arduino board. The pressure in the cylinder during operation is kept at 30psi, where the air is allowed to flow through the pipe line from air cylinder to slave cylinder.

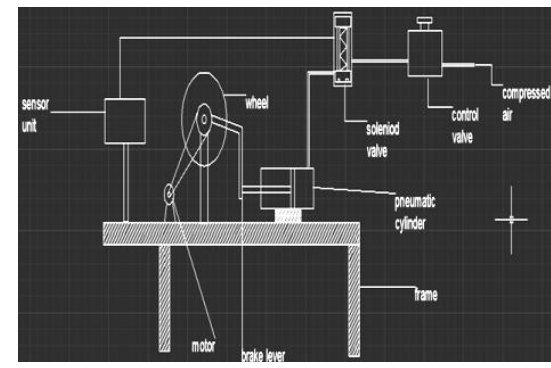

Fig1. Schematic diagram of the braking system using Arduino 
A wheel of diameter $330 \mathrm{~mm}$ is driven by a motor through a belt drive as shown in the Fig. 1 . Pneumatic brake system is used for applying the brake which is controlled by Arduino board. Audunio board receives signals from ultrasonic sensor when an obstacle is encountered on its path and activates the pneumatic valve which releases high pressure air on to the disc brake and thus reducing the acceleration on the wheel till it reaches halt position. A digital counting device is used to count the number of rotations of the wheel by a proximity sensor.

\subsubsection{Steps in Conducting Experiments}

a. Initially the motor is operated without any obstacle in front of the ultrasonic sensor till the rated speed is achieved.

b. Obstacle is placed in the path of ultrasonic sensor.

c. Note the rpm value when the pneumatic valve is opened and also note the final rpm value.

d. Change the speed of the wheel by controlling the input current to the motor such that the speed of the wheel is $10 \mathrm{~km} / \mathrm{hr}$ and increase in step of $5 \mathrm{~km} / \mathrm{hr}$ subsequently (ex. $10,15,20 \ldots . .50 \mathrm{~km} / \mathrm{hr}$ ).

e. Repeat the above step b, c and d till the speed of the wheel is $50 \mathrm{~km} / \mathrm{hr}$.
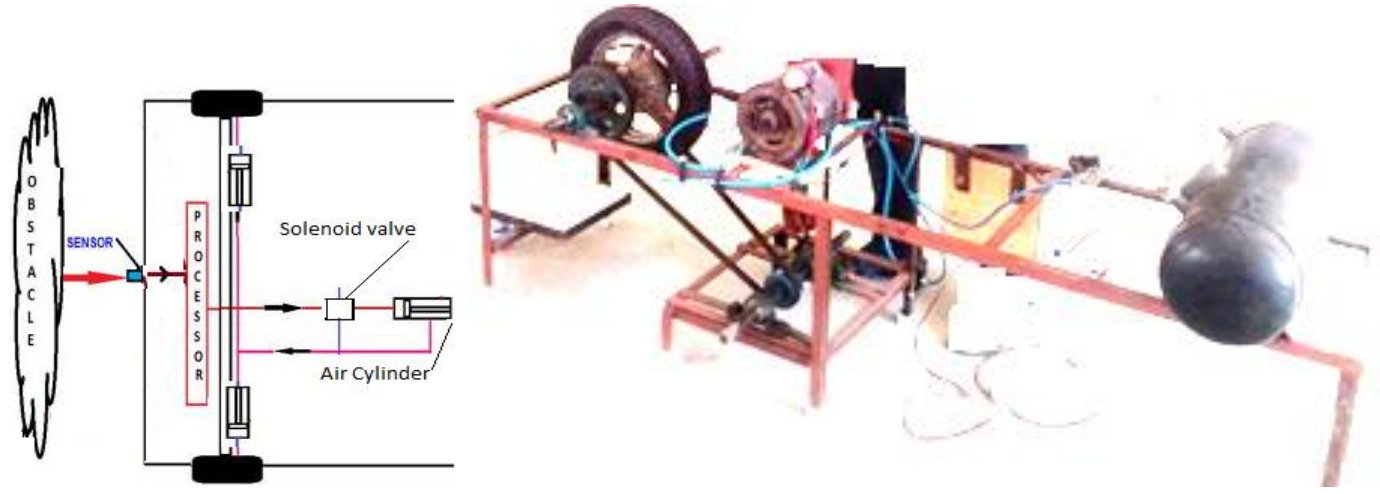

Fig2. Experimental setup

\subsection{Performance of Arduino Board System}

Arduino is a model stage (HC-SR04) in view of a simple to-utilize equipment and programming. It comprises of a circuit board, which can be customized (alluded to as a microcontroller) and instant programming called Arduino IDE (Integrated Development Environment), which is utilized to compose and transfer the PC code to the physical board.
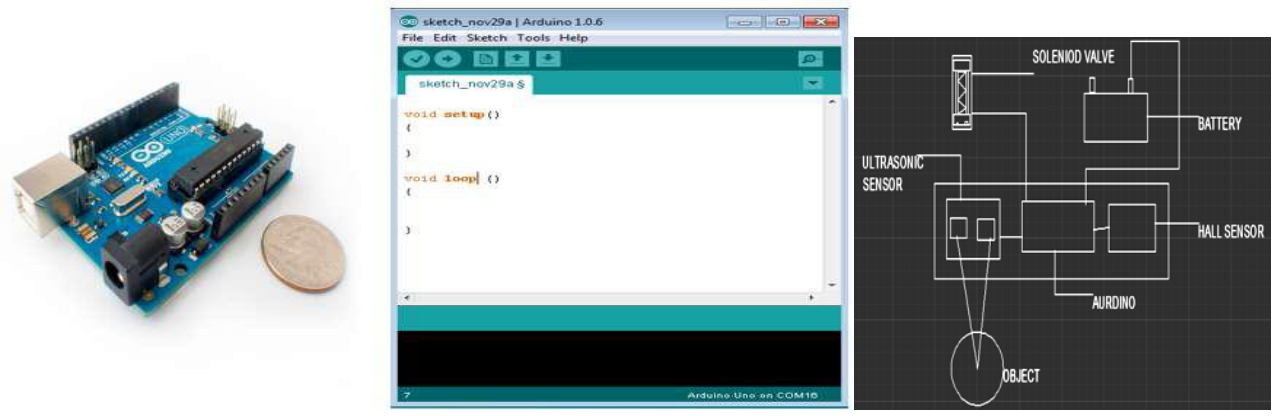

Fig3. Functional performance of Aurdino board

A miniaturized scale controller is a little PC on a solitary coordinated circuit containing a processor center, memory, and programmable info/yield peripherals.

1. Aurdino sheets can read simple or advanced information signals from various sensors and transform it into a yield, for example, actuating an engine, turning LED on/off, associate with the cloud and numerous different activities also, the Arduino IDE utilizes a streamlined rendition of $\mathrm{C}++$, making it less demanding to figure out how to program.

2. Dissimilar to most past programmable circuit sheets, Arduino does not require an additional bit of equipment (called a software engineer) keeping in mind the end goal to stack another code onto the board. You can basically utilize a USB link. 
3. At last, Arduino gives a standard shape factor that breaks the elements of the miniaturized scale controller into a more available bundle.

\section{RESULTS AND DISCUSSION}

In the present work, a model of ultrasonic separation estimation for stationary snag is acquired. What's more, controlling the speed of vehicle likewise to foreordained separation is appeared. A ultrasonic sensor, less expensive and less requesting of equipment than different sorts of sensors by and by utilized, for example, the sensors in light of PC vision or radar, is utilized to gauge the separation amongst vehicle and the snag. The relative speed of the vehicle as per the impediment is assessed utilizing back to back obstacle of the separation computed, these two amounts are utilized by the control framework to ascertain the activities on both the quickening agent and furthermore the brake, in this manner to alter the speed so as to keep up a protected separation to anticipate mischance. As ultrasonic sensors can identify any sort of snag, this framework can likewise anticipate impact of the vehicle with walkers, or can in any event diminish the wounds happening. Since the control framework does not utilize the total speed to ascertain the security separate as done by the present existing frameworks, the collaboration with car gadgets is constrained to activities on the quickening agent and brake. This issue, combined with the reality of lower cost of ultrasonic sensors contrasted and different sorts of sensors, could encourage the application and mounting of the framework in some low-end vehicles, enhancing solace and wellbeing and offer a bother free driving background at a lessened cost.

Table1. Data collection

\begin{tabular}{|l|l|l|l|}
\hline S.No. & rpm & Halt distance & Speed in $\mathrm{km} / \mathrm{hr}$ \\
\hline 1 & 160 & 0.726 & 10 \\
\hline 2 & 242 & 1.56 & 15 \\
\hline 3 & 324 & 2.07 & 20 \\
\hline 4 & 407 & 2.79 & 25 \\
\hline 5 & 485 & 4.15 & 30 \\
\hline 6 & 569 & 6.22 & 35 \\
\hline 7 & 650 & 10.37 & 40 \\
\hline 8 & 730 & 16.58 & 45 \\
\hline 9 & 812 & 22.8 & 50 \\
\hline
\end{tabular}

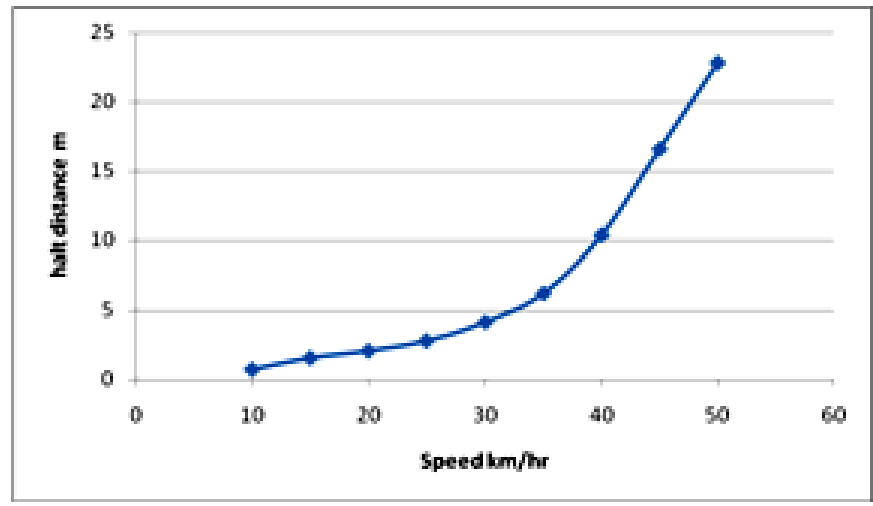

Fig4. Halt distance vs speed

The current supply in to the motor is controlled such that the rpm of the wheel will meet the speed conditions as listed in the table. 1 i.e. the speeds are fixed 10,15 , and 20 and so on, the rpm is calculated from angular velocity formula.

The halt distance is determined; when the pneumatic valve is opened till the wheel comes to the rest position.

\section{CONCLUSiON}

Experiments were conducted to find the distance at which the vehicle will come to rest position at various vehicle speeds. From the graph we understand the halt distance is less when the vehicle speed is less and vice versa. This clearly indicates that the vehicle is not coming to rest position abruptly, 
which is the required characteristic. The slope of the curve changes drastically after $30 \mathrm{~km} / \mathrm{hr}$ speed, the vehicle is being brought to halt within $5 \mathrm{~m}$ of distance. Higher speeds are not tested assuming that in low light or bad light conditions the rider will be cautious about his speed. Since the sensor are able to detect the obstacle and stops the vehicle, it will be very helpful when the driver is stressed and feel sleepy due to long journey, accidents due to such conditions may be reduced by this system. To conclude it was found if the distance between the object and the vehicle is less than $0.5 \mathrm{~m}$ the response of the system has failed resulting collision of the objects or need to be stopped abruptly, even at 10 $\mathrm{km} / \mathrm{hr}$. When the driver is inattentive and if the object distance is in between 0.5 to $25 \mathrm{~m}$ with the vehicle speed ranging between $10 \mathrm{~km} / \mathrm{hr}$ to $50 \mathrm{~km} / \mathrm{hr}$ collision can be avoided. Methodologies and conclusions that we exhibit are fairly preparatory and need facilitate critical examinations. While vehicle is taking a turn sensor can fail to recognize the required snag. This can be accomplished by mounting sensors on vehicle wheel that are equipped for measuring wheel turning. At show, this framework is promptly reasonable for programmed transmission. While rolling out a few improvements we can utilize this on any accessible vehicle.

\section{FUTURE WORK}

The present setup fails to detect the objects while taking a turn, but still this situation is minor as the driver will be cautious and will be moving at slow speeds and secondly if the object is coming in the straight direction but still is out of the signal range then the system will fail. To overcome this difficulty TWO sensors connected to the same board may be checked.

Additionally enhanced and exact writing computer programs are vital for constant operation. Utilization of smart slowing mechanism for basic dynamic condition should be broke down.

\section{REFERENCES}

[1] Hasan Oktem, Ilyas, U. \& Murat, C. (2018). Design, construction and performance of a novel brake pad friction tester. Elsevier: Measurement 115, 299-305.

[2] Kavatkar, M. T., Salve, H, \& Rah ate, M. (2017). Design and Analysis of Intelligent Braking System, International Journal of Engineering Development and Research (IJEDR1701019) 5 (1), 119-131.

[3] Duane, J., Li, R., Hou, L., \& GAO, H. (2017). Driver braking behavior analysis to improve autonomous emergency braking systems in typical Chinese vehicle-bicycle convicts. Elsevier: Accident Analysis and Prevention. 108, 74-82

[4] Chi-Min Liu, Yuan-Wei Wang, Cheng-Kuok Sung \& Chih-Yung Huang (2017). The Feasibility Study of Regenerative Braking Applications in Air Hybrid Engine, Elsevier: Energy Procedia 105, 4242-4247.

[5] Monika Davidekova \& Michal Greg us ml (2017). Nice, Berlin, London - if every car had autonomous emergency braking system for forward collisions avoidance, Elsevier: Procedia Computer Science 110, 386-393.

[6] Vytenis, S. and Edgar, S. (2016). Research of the vehicle brake testing efficiency, Elsevier: Procedia Engineering 134, 452-458.

[7] Pasquale, S., Matteod'A., Maria, A. B., Rolando, S. and Anita F (2016). Experimental framework for simulators to study driver cognitive distraction: Break reaction time in different levels of arousal. Elsevier: Transportation Research Procedia 14, 4410-4419

[8] Monisha S., Ratan, R., \& Luthra, S.K. (2015). Design \& Development of Smart Ultrasonic Distance Measuring Device. International Journal of Innovative Research in Electronics and Communications (IJIREC) 2 (3), 19-23

[9] Shanmathi, S., Kamalanathan \& C., Ramesh, S.M. (2014). Arduino based vehicle control system using CAN Protocol. International journal for advance research in engineering and technology (IJARET) 2 (XI), 16-19.

[10] Bhatt, P. P., Kunjan A. C \& Kaushal A. C (2014). Programming for Automatic over speed Control System for Safety in Automobiles. International Journal on Theoretical and Applied Research in Mechanical Engineering (IJTARME) 1 (3) 56-61.

[11] Alessio Carullo \& Marco Parvis (2001). An Ultrasonic Sensor for Distance Measurement in Automotive Applications, IEEE Sensors Journal, 1(2), 143-147. 


\section{AUTHORS' BIOGRAPHY}

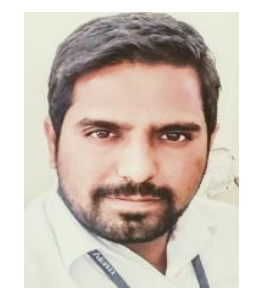

P. Bhaskara, is a Asst. Professor of Department of Mechanical Engineering in VEMU Institute of Technology, India. He has published several research journal and conference papers in the areas of Automobile and Industrial Engineering. His other areas of interest are Robotics, and applications of decision-making models. He is a life member of International Association of Engineers (IAENG).

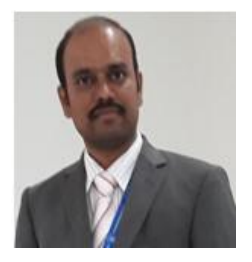

Eriki Ananda.K, currently working as a Professor in department of mechanical engineering and Director of R\&D in VEMU Institute of Technology, AP-India, he has published more than 30 journals and conference papers since 2010. His research area includes titanium alloys, Nanotechnology, Simulation Modeling and Analysis. He is a member of International Association of Engineers and Institution of Engineers Malaysia. He is also an Advisory/Editorial board member of IIER, IASTEM, IJMSE, OGCE, IJMEA, and IISEM, reviewer for IJSTM, IJEX and IJMCMR

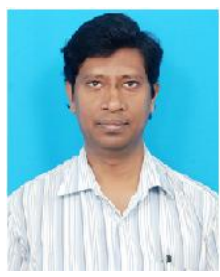

Venkataramana. V, is Assoc. Professor, Department of Mechanical Engineering in VEMU Institute of Technology, India. He has published several research journal and conference papers in the areas of Supply chain management, Aluminum forms and Automobile. His other areas of interest are operations research, and applications of decision-making models. He is a life member of Indian Society of Technical Education (ISTE).

Citation: Eriki Ananda. K et.al. (2018)" Arduino Based Automated Braking Control System to Enhance the Safety at Low Light and Long Stressed Drive Conditions", International Journal of Modern Studies in Mechanical Engineering, 4(2), pp.1-6. DOI: http://dx.doi. org/10.20431/2454-9711.0402001

Copyright: () 2018 Eriki Ananda. K, This is an open-access article distributed under the terms of the Creative Commons Attribution License, which permits unrestricted use, distribution, and reproduction in any medium, provided the original author and source are credited. 